Plant Tissue Cult. \& Biotech. 27(1): 21-31, 2017 (June)

$\overline{\text { PTC\&B }}$

\title{
Regeneration of Asparagus officinalis L. Through Embryogenic Callus
}

\section{Mustafa Abul Kalam Azad* and Muhammad Nurul Amin}

Department of Botany, University of Rajshahi, Rajshahi-6205, Bangladesh

Key words: Somatic embryo, Hypocotyl explants, Asparagus officinalis

\begin{abstract}
A plant regeneration system was established from hypocotyl explants of in vitro grown seedlings of $A$. officinalis and in vitro proliferated shoots, respectively through somatic embryogenesis and embryogenic calli. Somatic embryogenesis was significantly influenced by the types of plant growth regulators. Embryogenic calli with somatic embryos developed well in MS supplemented with $2.0-4.0 \mu \mathrm{M}$ BAP and $1.0-4.0 \mu \mathrm{M}$ 22,4-D, NAA or IBA. The highest frequency $(95.3 \%)$ of embryogenic calli and 55.2 somatic embryos formation were obtained when the MS was amended with $4.0 \mu \mathrm{M}$ BAP and 2.0 $\mu \mathrm{M} 2,4-\mathrm{D}$. The best embryo germination occurred in $1.0 \mu \mathrm{M}$ BAP supplemented MMS. The highest $97.2 \%$ of shoot proliferation was observed in embryogenic calli in MS medium containing $2.0 \mu \mathrm{M}$ BAP and $1.0 \mu \mathrm{M}$ IBA. In vitro grown shoots were rooted in MMS with 1.0 - 2.0 $\mu$ M IBA. Regenerants were transferred to vermicompost and successfully established under an ex vitro environment in garden soil with $80 \%$ survival rate.
\end{abstract}

\section{Introduction}

The vegetable asparagus (Asparagus officinalis L.) is a dioecious perennial herb of Asparagaceae (formerly Liliaceae). A. officinalis is native to Europe, Asia and north-western Africa. It is grown worldwide as a crop, particularly in North and South America, China and Europe. The male plant of the species produces well developed and succulent spring stalks, popularly known as spears /strains. Only young shoots of asparagus are commonly eaten. It is the best known and economically important garden species cultivated as a green tender vegetable (Grubben and Denton 2004, USDA 2007).

*Author for correspondence: <drmakazad@gmail.com>. 
A. officinalis is known to be a strong diuretic and is used in the treatment of urinary problems such as cystitis. It is also useful in the treatment of rheumatic conditions, is a mild laxative and sedative, and is considered useful in the treatment of a range of maladies from arthrosis to tuberculosis. The amino acid asparagine gets its name from asparagus, as the asparagus plant is relatively rich in this compound (Leung and Foster 1980, Jang et al. 2004). Asparagus is also a rich source of glutathione, a powerful antioxidant that is known to boost the immune system, reduce inflammation and maintain the health of the liver (Kappor 2001, Chrubasik et al. 2006, Dartsch 2008a,b, Pam 2010). Individual tree varieties which are established in vitro through somatic embryogenesis and propagated through the production of somatic embryos are analogous to seeds.

A. officinalis is normally propagated through seeds and rhizomes; but this is a slow process that results in smaller number of new propagules (Reuther 1984). To meet the growing demand for this species poses a major challenge, in vitro propagation can be of immense value in offsetting the pressure on natural populations, thereby conserving the species. The present study was aimed at developing an efficient propagation protocol for the production of clonally uniform plants through somatic embryogenesis and organogenesis method (Makris and Rossiter 2001).

\section{Materials and Methods}

Seeds of Asparagus officinalis were collected from Japan. These seeds were surface-sterilized with $70.0 \% \mathrm{EtOH}$ for $3 \mathrm{~min}$. Sterilized seeds were germinated on hormone-free MS. The seeds germinated within 3 weeks and gave rise to shoots that developed two to three nodes five to six weeks later. Shoots were then propagated by subculturing single-node cuttings at 4-week intervals in MS with BAP $(2.0-4.0 \mu \mathrm{M})$.

Hypocotyl explants were prepared from 6-week-old aseptically grown seedlings. These explants were cultured in MS containing different concentrations of BAP $(2.0-4.0 \mu \mathrm{M})$ in combination with either 2,4-D $(1.0-4.0 \mu \mathrm{M})$, NAA or IBA for the induction of embryogenic calli and somatic embryos. Hypocotyl explants were also cultured in B5 (Gamborg et al. 1968), MMS (half strength of MS basal salts), and WPM (Lloyd and McCown 1981) media, with the addition of $4.0 \mu \mathrm{M}$ BAP plus $2.0 \mu \mathrm{M} 2,4-\mathrm{D}$, NAA or IBA to determine the effects of media on somatic embryogenesis. For the germination of somatic embryos (SEs), the individual embryos were cultured in an MMS basal medium with $2.0 \%$ sucrose and a low concentration $(0.5-2.0 \mu \mathrm{M})$ of BAP and $\mathrm{Kn}, 10-30 \% \mathrm{CW}$ (Coconut water) or without the addition of any plant-growth regulators. 
The embryogenic calli (approx. 0.5 - $1.0 \mathrm{~g}$ ) were transferred to MS medium supplemented with various concentrations and combinations of BAP (2.0 - 4.0 $\mu \mathrm{M})$ and NAA or IBA $(0.5-2.0 \mu \mathrm{M})$ for adventitious shoot regeneration. The data were recorded after eight weeks of culture initiation: percentage of shoot formation, number of total shoots per culture, and average length of shoots per culture. Embryogenic calli-derived shoots were rooted in MMS supplemented with different concentrations $(0.5-4.0 \mu \mathrm{M})$ of IBA, NAA, or IAA. All culture media were adjusted to $\mathrm{pH} 5.7 \pm 0.1$, fortified with $3.0 \%$ sucrose $(\mathrm{w} / \mathrm{v}$ ) (except embryo germination medium), and gelled with $8.0 \%$ agar. The cultures were grown at $25 \pm 1^{\circ} \mathrm{C}$ under the illumination of cool-white fluorescence tubular lamp with a light intensity of $50 \mu \mathrm{mol} \cdot \mathrm{m}^{-2} \cdot \mathrm{s}^{-1}$ for a $16 \mathrm{hrs}$ photoperiod.

Twenty replicates of all experiments were conducted. Experiments were repeated four times. The effects of different treatments were quantified, and the data were analyzed using ANOVA. Tukey's multiple comparison was used to distinguish differences between treatments.

\section{Results and Discussion}

Callusing started at the different points on the surfaces of the hypocol explants after 3 - 4 weeks of culture, irrespective of the kinds of growth regulators used in this experiment. The calli successfully produced globular to early stage of embryos (Fig. 1A-B). Present experiment reveled that BAP with 2,4-D or NAA was the most efficient combination for producing embryogenic calli and somatic embryos from hypocotyl explants of A. officinalis. MS with BAP $(4.0 \mu \mathrm{M})$ plus 2,4-D $(2.0 \mu \mathrm{M})$ or NAA enhanced embryogenic callus formation and somatic embryo proliferation from the hypocotyl, the frequencies was 95.3 and $85.0 \%$, respectively (Table 1). The highest average number of somatic embryos per culture was recorded as 55.2 and 38.3 from hypocotyl explants. The proliferation of embryogenic calli was faster in the media with BAP plus 2,4-D than in those with BAP plus NAA or BAP plus IBA which required a short period to produce an appreciable number of calli where the initial calli were white-greenish, nodular, and friable in morphological nature. Tawfik and Noga (2002) reported that 2,4-D and $\mathrm{Kn}$ was the most suitable combination for producing embryogenic calli in Cuminum cyminum where this combination failed to induce any somatic embryos. When the calli subcultured in PGRs free MS, they produced somatic embryos. Our experiment showed that BAP with 2,4-D combination produced embryogenic calli simultaneously produced somatic embryos where no embryo formation was observed in PGRs free medium. 
For producing somatic embryos as well as embryogenic calli from hypocotyl explants, different types of basal media were also used in this experiments. Among the different basal media treatments, MS containing 4.0 $\mu \mathrm{M}$ BAP plus 2.0 $\mu \mathrm{M}$ 2,4-D induced embryo differentiation at high rates, and the frequencies of embryogenic callus formation was 95.3. The lowest number (10.1) of embryo development was obtained in cultures in WPM medium supplemented with 4.0 $\mu \mathrm{M}$ BAP and $2.0 \mu \mathrm{M}$ IBA. Considerable embryogenic callus and SE formation were achieved from hypocotyl explant of A. officinalis in MMS and B5 medium having $4.0 \mu \mathrm{M}$ BAP plus $2.0 \mu \mathrm{M}$ 2,4-D.

Table 1. Effects of plant growth regulators and culture media on embryogenic callus and somatic embryo formation from hypocotyl explants.

\begin{tabular}{lccc}
\hline Type of medium & PGR* & $\begin{array}{c}\text { Embryogenic callus formation } \\
(\%)\end{array}$ & $\begin{array}{c}\text { No. of embryos } \\
\text { MS }\end{array}$ \\
& PGR1 & $95.3 \pm 1.4 \mathrm{a}$ & $55.2 \pm 1.1 \mathrm{a}$ \\
& PGR2 & $85.0 \pm 1.1 \mathrm{~b}$ & $38.3 \pm 1.2 \mathrm{~b}$ \\
& PGR3 & $65.5 \pm 1.2 \mathrm{c}$ & $32.1 \pm 1.4 \mathrm{~b}$ \\
MMS & PGR1 & $60.2 \pm 15 \mathrm{c}$ & $40.1 \pm 1.5 \mathrm{~b}$ \\
& PGR2 & $51.1 \pm 2.0 \mathrm{~d}$ & $38.5 \pm 1.2 \mathrm{~b}$ \\
B5 & PGR3 & $40.3 \pm 1.4 \mathrm{e}$ & $25.1 \pm 1.4 \mathrm{c}$ \\
& PGR1 & $62.1 \pm 1.6 \mathrm{c}$ & $41.1 \pm 1.1 \mathrm{~b}$ \\
& PGR2 & $53.2 \pm 1.3 \mathrm{~d}$ & $35.2 \pm 0.5 \mathrm{~b}$ \\
WPM & PGR3 & $42.2 \pm 1.1 \mathrm{e}$ & $26.1 \pm 1.0 \mathrm{c}$ \\
& PGR1 & $45.2 \pm 2.0 \mathrm{e}$ & $20.2 \pm 0.5 \mathrm{c}$ \\
& PGR2 & $36.3 \pm 1.1 \mathrm{e}$ & $15.2 \pm 1.1 \mathrm{~d}$ \\
& PGR3 & $28.3 \pm 1.3 \mathrm{f}$ & $10.1 \pm 1.4 \mathrm{e}$ \\
\hline
\end{tabular}

Values represent means \pm standard error of 20 explants per treatment in four repeated experiments. Means followed by the same letters are not significantly different by Tukey's multiple comparison test at 0.05 probability level. ${ }^{*}$ PGR1 $=4.0 \mu \mathrm{M}$ BAP $+2.0 \mu \mathrm{M} 2,4-\mathrm{D} ; \quad$ PGR2 $=4.0 \mu \mathrm{M}$ BAP + $2.0 \mu \mathrm{M}$ NAA; PGR3 $=4.0 \mu \mathrm{M}$ BAP $+2.0 \mu \mathrm{M}$ IBA

The number, color, size, shape, and appearance time of the induced embryogenic calli varied among the rice cultivars depending on the type of basal medium (LS, MS, N6). Lee et al. (2002) reported that supplemented of N6 medium was most efficient for induction of the embryogenic calli, where the overall rates ranged was from 30 to $56 \%$. In that medium Kn was more effective for shoot regeneration compared with $\mathrm{BA}$, while the highest shoot regeneration frequencies were $67-77 \%$ when cytokinin was combined with high concentration $(10.74 \mu \mathrm{M})$ of NAA. In our study we used four types basal medium (MS, MMS, B5 and WPM) and three types of plant growth regulators. Among these media and plant growth regulators MS and 4.0 $\mu \mathrm{M}$ BAP plus $2.0 \mu \mathrm{M}$ 2,4-D were the most efficient basal 
medium and plant growth regulator, respectively for induction of embryogenic callus and somatic embryos.

Individual embryos were easily separated from the maternal tissues, as they were loosely attached at the radicle end to the mother explant (Fig. 1B). Such embryos were easily converted into plantlets in MMS containing 2.0\% sucrose without the addition of any PGRs. In this medium, the highest embryo germination rate of 86.3 was observed. On the other hand, addition of $20 \% \mathrm{CW}$ in MS showed a considerable higher germination rate $(70.5 \%)$, which was followed by $1.0 \mu \mathrm{M} \mathrm{Kn}$ (Table 2). Moreover, satisfactory embryo germination was observed on MS with a low $(0.5 \mu \mathrm{M})$ concentration of NAA (data not shown in Table 2). When SEs of A. officinalis were maintained in an embryo-induction medium (MS + $4.0 \mu \mathrm{M}$ BAP $+2.0 \mu \mathrm{M} 2,4-\mathrm{D}$, NAA or IBA without transfer for approximately 3 months, about $20.0-45.0 \%$ (data not shown) of the embryos germinated and developed into normal plantlets, probably due to

Table 2. Effects of cytokinins on somatic embryo germination. Values represent the mean of 20 replicates per treatment in four repeated experiment.

\begin{tabular}{lccc}
\hline PGR & $\begin{array}{c}\text { Concentrations of PGR } \\
(\mu \mathrm{M})\end{array}$ & $\begin{array}{c}\text { Embryo } \\
\text { germination }(\%)\end{array}$ & $\begin{array}{c}\text { Survival rate of } \\
\text { embryos }(\%)\end{array}$ \\
\hline Control $(\mathrm{HO})$ & 0.0 & $35.2 \pm 1.0 \mathrm{e}$ & $70.3 \pm 1.8 \mathrm{~b}$ \\
BAP & 0.5 & $78.5 \pm 1.2 \mathrm{~b}$ & $73.5 \pm 1.1 \mathrm{~b}$ \\
& 1.0 & $86.3 \pm 1.6 \mathrm{a}$ & $65.1 \pm 1.6 \mathrm{~b}$ \\
& 2.0 & $55.5 \pm 1.3 \mathrm{~d}$ & $51.2 \pm 0.7 \mathrm{c}$ \\
$\mathrm{Kn}$ & 0.5 & $56.3 \pm 0.8 \mathrm{~d}$ & $61.2 \pm 1.5 \mathrm{~b}$ \\
& 1.0 & $65.4 \pm 1.4 \mathrm{c}$ & $53.1 \pm 1.3 \mathrm{c}$ \\
$\mathrm{CW}$ & 2.0 & $38.0 \pm 1.1 \mathrm{e}$ & $35.6 \pm 0.7 \mathrm{~d}$ \\
& $10 \%$ & $60.2 \pm 1.0 \mathrm{~d}$ & $66.1 \pm 1.2 \mathrm{~b}$ \\
& $20 \%$ & $70.5 \pm 1.0 \mathrm{c}$ & $72.7 \pm 1.7 \mathrm{~b}$ \\
\hline
\end{tabular}

Values represent means \pm standard error of 20 explants per treatment in four repeated experiments. Means followed by the same letters are not significantly different by Tukey's multiple comparison test at 0.05 probability level.

desiccation caused by the increased osmoticum in the solid medium. Junaid et al. (2006) reported that somatic embryo maturation and germination in Catharanthus roseaus occurred when $3.0 \%$ sucrose and $2.22 \mu \mathrm{M}$ BAP supplement MS was used. In our study, SEs that were induced in a 2,4-D-containing medium developed only shoots but failed to produce any roots. During the maturation stage the somatic embryos undergo various morphological and biochemical changes. The synthesis and accumulation of storage and late embryogenesis abundant proteins during somatic embryos maturation are usually regulated through stress induced 

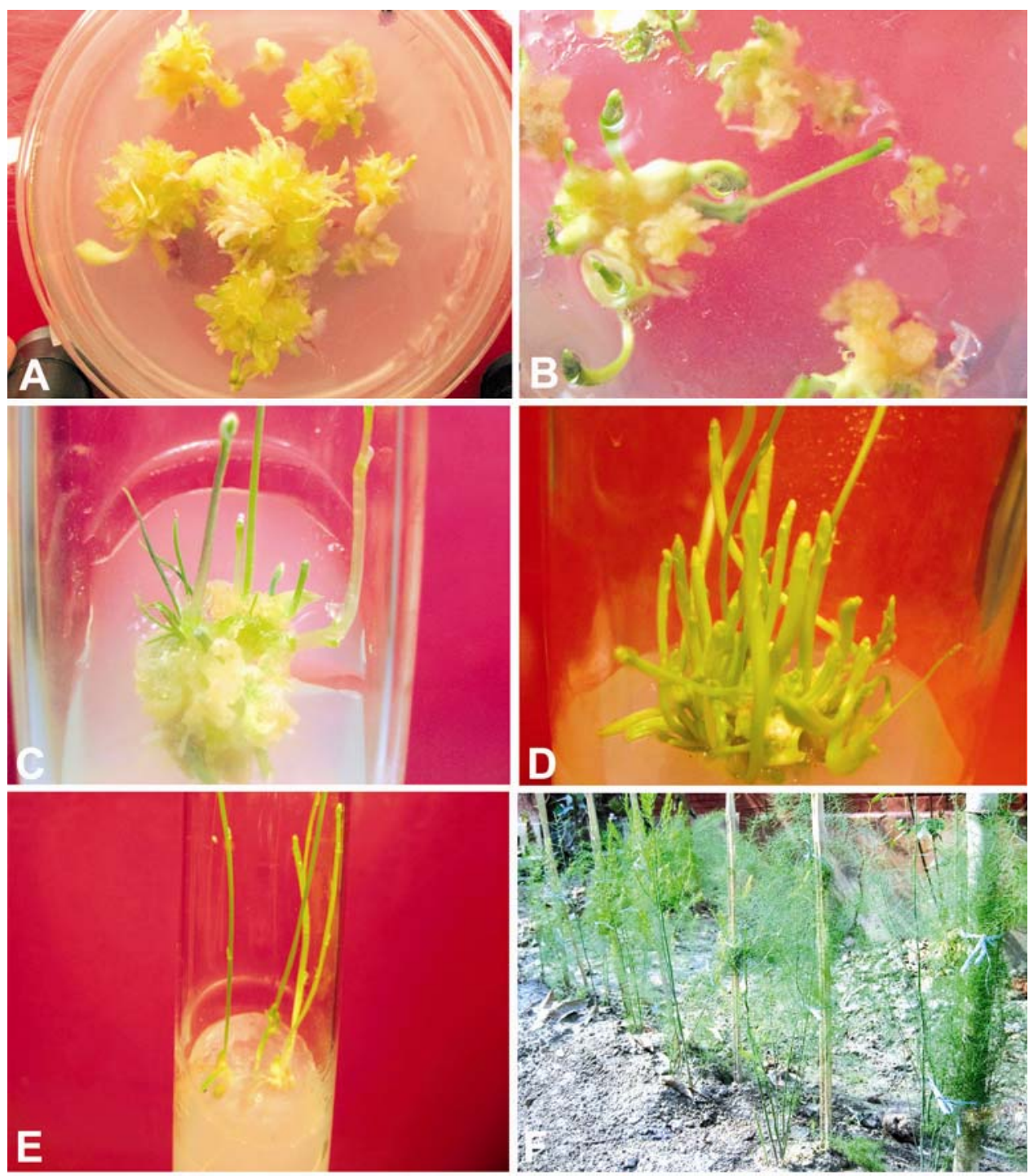

Fig. 1. Plant regeneration through somatic embryo and embryogenic calli. A. Proliferation of somatic embryos on MS containing BAP $(4.0 \mu \mathrm{M})$ plus 2,4-D $(2.0 \mu \mathrm{M})$ after eight weeks. B. Somatic embryo germination on MS containing BAP $(1.0 \mu \mathrm{M})$ after six weeks. C-D. Development of adventitious shoots from embryogenic calli on MS containing BAP $(2.0 \mu \mathrm{M})$ plus IBA $(1.0 \mu \mathrm{M})$ after seven 7 weeks $(C)$ and ten weeks (D). E. Rooting of in vitro proliferated shoots on MMS containing IBA $(2.0 \mu \mathrm{M})$ after six weeks. F. Acclimated plants growing under field conditions after three months of transfer to soil.

through stress induced gene expression. Seventy per cent of somatic embryos germinated into plantlets within six weeks. Fifty regenerated plants were transplanted to small plastic pots containing vermicompost and kept in a culture room for 8 weeks for hardening under diffuse light (16 hrs photoperiod; 
temperature $25 \pm 1^{\circ} \mathrm{C}$; relative humidity $65.0 \%$ ). The plants were irrigated once in 3 days and fertilized with MS ( $1 / 4$ strength) basal-salt solutions devoid of sucrose and myo-inositol at weekly intervals. Then, the plants were transferred to pots containing garden soil and reared in the polythene-tent. Irrigation and fertilizer treatment were continued. Out of 50 plants transferred, 40 survived after one month of transplantation to the polythene-tent. The surviving plantlets did not show any detectable variations in morphological or growth characteristics from the donor plants.

Table 3. Effects of different concentrations and combinations of cytokinin and auxin on adventitious shoot regeneration embryogenic calli.

\begin{tabular}{|c|c|c|c|}
\hline $\begin{array}{l}\text { Plant growth } \\
\text { regulators }(\mu \mathrm{M})\end{array}$ & $\begin{array}{c}\text { Shoot formation } \\
(\%)\end{array}$ & $\begin{array}{c}\text { Total shoots/ } \\
\text { culture }\end{array}$ & $\begin{array}{c}\text { Av. length of shoots/ } \\
\text { culture }(\mathrm{cm})\end{array}$ \\
\hline \multicolumn{4}{|l|}{$\mathrm{BAP}+\mathrm{IBA}$} \\
\hline $2.0+0.5$ & $94.5 \pm 1.1 \mathrm{a}$ & $45.3 \pm 1.0 \mathrm{~b}$ & $6.4 \pm 1.3 b$ \\
\hline+1.0 & $97.2 \pm 2.0 \mathrm{a}$ & $50.1 \pm 1.2 \mathrm{a}$ & $8.1 \pm 1.2 \mathrm{a}$ \\
\hline+2.0 & $60.6 \pm 1.2 \mathrm{e}$ & $15.2 \pm 1.0 \mathrm{f}$ & $5.5 \pm 1.7 \mathrm{c}$ \\
\hline $4.0+0.5$ & $84.1 \pm 1.1 \mathrm{~b}$ & $35.4 \pm 1.1 \mathrm{c}$ & $6.3 \pm 1.8 \mathrm{~b}$ \\
\hline+1.0 & $90.8 \pm 1.4 \mathrm{a}$ & $42.3 \pm 1.2 \mathrm{~b}$ & $6.6 \pm 0.6 b$ \\
\hline+2.0 & $78.5 \pm 1.7 \mathrm{c}$ & $25.6 \pm 1.1 \mathrm{e}$ & $5.1 \pm 1.1 \mathrm{c}$ \\
\hline \multicolumn{4}{|l|}{$\mathrm{BAP}+\mathrm{NAA}$} \\
\hline $2.0+0.5$ & $77.3 \pm 0.5 c$ & $41.4 \pm 1.1 \mathrm{~b}$ & $6.7 \pm 1.2 b$ \\
\hline+1.0 & $85.1 \pm 1.1 \mathrm{~b}$ & $48.3 \pm 1.3 \mathrm{a}$ & $7.4 \pm 1.0 \mathrm{~b}$ \\
\hline+2.0 & $52.3 \pm 1.3 \mathrm{e}$ & $10.2 \pm 1.5 \mathrm{f}$ & $3.2 \pm 0.3 \mathrm{e}$ \\
\hline $4.0+0.5$ & $78.2 \pm 1.7 \mathrm{c}$ & $32.3 \pm 1.1 \mathrm{~d}$ & $5.1 \pm 1.1 \mathrm{c}$ \\
\hline+1.0 & $83.0 \pm 1.5 \mathrm{~b}$ & $38.7 \pm 1.7 \mathrm{~b}$ & $6.2 \pm 0.9 b$ \\
\hline+2.0 & $77.3 \pm 1.0 \mathrm{c}$ & $20.4 \pm 1.2 \mathrm{f}$ & $4.9 \pm 1.1 \mathrm{c}$ \\
\hline \multicolumn{4}{|l|}{$\mathrm{Kn}+\mathrm{IBA}$} \\
\hline $2.0+0.5$ & $61.2 \pm 1.1 \mathrm{e}$ & $16.4 \pm 1.4 \mathrm{f}$ & $4.4 \pm 1.7 \mathrm{~d}$ \\
\hline+1.0 & $60.1 \pm 1.4 \mathrm{e}$ & $18.2 \pm 1.5 \mathrm{f}$ & $5.9 \pm 1.5 c$ \\
\hline+2.0 & $25.4 \pm 1.2 \mathrm{~h}$ & $8.2 \pm 1.0 \mathrm{f}$ & $3.5 \pm 1.2 \mathrm{e}$ \\
\hline $4.0+0.5$ & $55.4 \pm 1.0 \mathrm{e}$ & $12.2 \pm 1.2 \mathrm{f}$ & $4.1 \pm 1.6 \mathrm{~d}$ \\
\hline+1.0 & $65.3 \pm 1.6 \mathrm{~d}$ & $20.4 \pm 1.2 \mathrm{f}$ & $4.4 \pm 1.9 \mathrm{~d}$ \\
\hline+2.0 & $56.2 \pm 1.0 \mathrm{e}$ & $9.4 \pm 1.1 \mathrm{f}$ & $3.9 \pm 1.0 \mathrm{~d}$ \\
\hline \multicolumn{4}{|l|}{$\mathrm{Kn}+\mathrm{NAA}$} \\
\hline $2.0+0.5$ & $45.3 \pm 0.8 \mathrm{f}$ & $12.5 \pm 1.4 \mathrm{f}$ & $4.3 \pm 1.2 \mathrm{~d}$ \\
\hline+1.0 & $56.7 \pm 1.2 \mathrm{e}$ & $17.3 \pm 1.7 \mathrm{f}$ & $5.7 \pm 1.5 \mathrm{c}$ \\
\hline+2.0 & $16.4 \pm 1.3 \mathrm{i}$ & $7.4 \pm 1.2 \mathrm{f}$ & $2.6 \pm 1.3 \mathrm{f}$ \\
\hline $4.0+0.5$ & $32.3 \pm 1.7 \mathrm{~g}$ & $10.3 \pm 1.2 \mathrm{f}$ & $4.7 \pm 1.1 \mathrm{c}$ \\
\hline+1.0 & $57.1 \pm 1.1 \mathrm{e}$ & $16.5 \pm 0.9 \mathrm{f}$ & $5.3 \pm 0.6 c$ \\
\hline+2.0 & $33.3 \pm 1.0 \mathrm{~g}$ & $6.9 \pm 1.2 \mathrm{f}$ & $3.1 \pm 1.5 \mathrm{e}$ \\
\hline
\end{tabular}

Values represent means \pm standard error of 20 explants per treatment in four repeated experiments. Means followed by the same letters are not significantly different by Tukey's multiple comparison test at 0.05 probability level. 
Hypocotyl-derived embryogenic calli produced adventitious shoots in the MS with either of $2.0 \mu \mathrm{M}$ BAP plus $1.0 \mu \mathrm{M}$ IBA or NAA; and $4.0 \mu \mathrm{M} \mathrm{Kn}$ plus 1.0 $\mu \mathrm{M}$ IBA or NAA, where the shoot formation rates were 97.2, 85.1, 65.3 and $57.1 \%$, respectively (Table 3). The combination of $2.0 \mu \mathrm{M}$ BAP with $1.0 \mu \mathrm{M}$ IBA gave the highest frequency (97.2) of shoot proliferation, $50.1 \pm 1.2$ shoots per culture, and the highest average length, $8.1 \pm 1.2 \mathrm{~cm}$ (Fig. 1C,D). On the other hand, considerable shoot proliferation $(85.1 \%)$ was found at $2.0 \mu \mathrm{M}$ BAP plus $1.0 \mu \mathrm{M}$ NAA. The lowest performance was shown in Kn plus IBA or NAA formulations. Similar results were found in leaf and stem nodes explants of Lilium (Bacchetta et al. 2003), callus derived protoplast in Phellodendron amurense (Azad 2012), cotyledon explant in Acacia mangium (Shahinozzaman et al. 2013), epicotyl and internode explants in Cajanus cajan (Azad and Amin 2013). Our study also revealed that BAP-IBA and BAP-NAA formulation was better than Kn-IBA or Kn-NAA formulations. In the present study it was noticed that the stimulation of shoot regeneration by the PGR combinations was significantly higher than the 2 : 1 cytokinin/auxin ratio and the hypocotyl-derived embryogenic calli showed better response for shoot regeneration than internode-derived embryogenic calli.

Table 4. Effects of auxin in MS on in vitro adventitious root formation from microcuttings.

\begin{tabular}{lcccc}
\hline $\begin{array}{l}\text { Type of } \\
\text { auxin }\end{array}$ & $\begin{array}{c}\text { Con. of auxin } \\
(\mu \mathrm{M})\end{array}$ & $\begin{array}{c}\text { Rooted cuttings } \\
(\%)\end{array}$ & $\begin{array}{c}\text { No. of roots / } \\
\text { rooted cutting }\end{array}$ & $\begin{array}{c}\text { Av. length of } \\
\text { roots }(\mathrm{cm})\end{array}$ \\
\hline \multirow{3}{*}{ IBA } & 0.5 & $70.4 \pm 1.5 \mathrm{~d}$ & $3.1 \pm 1.1 \mathrm{c}$ & $3.2 \pm 1.1 \mathrm{e}$ \\
& 1.0 & $90.4 \pm 1.3 \mathrm{~b}$ & $5.2 \pm 1.3 \mathrm{~b}$ & $4.1 \pm 1.2 \mathrm{c}$ \\
& 2.0 & $98.3 \pm 2.1 \mathrm{a}$ & $6.4 \pm 1.7 \mathrm{a}$ & $5.5 \pm 1.8 \mathrm{a}$ \\
& 4.0 & $40.5 \pm 2.2 \mathrm{e}$ & $3.5 \pm 1.8 \mathrm{c}$ & $2.3 \pm 1.3 \mathrm{e}$ \\
NAA & 0.5 & $67.3 \pm 1.8 \mathrm{~d}$ & $2.4 \pm 1.1 \mathrm{~d}$ & $4.5 \pm 1.5 \mathrm{~b}$ \\
& 1.0 & $82.4 \pm 2.0 \mathrm{c}$ & $3.3 \pm 1.2 \mathrm{c}$ & $4.1 \pm 1.9 \mathrm{c}$ \\
& 2.0 & $63.1 \pm 1.1 \mathrm{~d}$ & $2.2 \pm 1.4 \mathrm{~d}$ & $3.6 \pm 1.7 \mathrm{~d}$ \\
IAA & 4.0 & - & - & - \\
& 0.5 & $35.2 \pm 1.6 \mathrm{e}$ & $1.1 \pm 1.4 \mathrm{e}$ & $2.5 \pm 1.6 \mathrm{e}$ \\
& 1.0 & $38.2 \pm 1.7 \mathrm{e}$ & $1.5 \pm 1.2 \mathrm{e}$ & $2.8 \pm 1.6 \mathrm{e}$ \\
& 2.0 & $42.5 \pm 2.1 \mathrm{e}$ & $2.4 \pm 1.6 \mathrm{~d}$ & $3.1 \pm 1.6 \mathrm{e}$ \\
& 4.0 & $45.6 \pm 1.4 \mathrm{e}$ & $3.4 \pm 1.5 \mathrm{c}$ & $3.7 \pm 1.5 \mathrm{~d}$ \\
\hline
\end{tabular}

' - indicates no response. Values represent means \pm standard error of 20 explants per treatment in four repeated experiments. Means followed by the same letters are not significantly different by Tukey's multiple comparison test at 0.05 probability level.

Micro-cuttings $(1.5-2.0 \mathrm{~cm}$ length) were transferred for rooting to an agar gelled MMS with 0.5, 1.0, 2.0, and 4.0 $\mu \mathrm{M}$ IBA, NAA, or IAA supplementation. Among the different auxins used, IBA was found to be the best for root induction. The percentage of root induction and the number of roots per shoot were also 
highly influenced by the concentration and type of auxin. The maximum rooting of cultures was $98.3 \%$ with $6.4 \pm 1.7$ number of roots per shoot, and $5.5 \pm 1.8 \mathrm{~cm}$ average length of roots when the shoots were cultured in a medium containing $2.0 \mu \mathrm{M}$ IBA (Table 4). Although the media containing NAA and IAA also resulted in root formation, the rooting response was not as good as that in the media containing IBA. The maximum rooting frequency was $82.4 \%$ in was observed in medium supplemented with $1.0 \mu \mathrm{M}$ NAA and $45.6 \%$ in the medium supplemented with $4.0 \mu \mathrm{M}$ IAA. No rooting was found in the $4.0 \mu \mathrm{M}$ NAA-supplemented medium. In this case, only calli were formed at the cut margin of the shoots. Being a stable nature, IBA is the preferred auxin for adventitious root initiation in many species (Yadav et al. 1990, Amin et al. 1992, Azad et al. 2005a,b). In addition, Litz and Jaiswal (1990) found IBA to be a superior auxin to IAA or NAA for the in vitro rooting of apple shoots. In the case of $A$. officinalis, IBA is also considered to be the best auxin for rooting from microcuttings. In this experiment, the minimum number of days required for rooting was 7 , and the maximum was 25 from culture initiation. The rooting frequency increased gradually with the increase in the culture incubation period. It is a common practice to transfer shoots from a high strength media to less concentrated solutions to induce rooting (Bopana and Saxena 2008). In many species such as Dendrocalamus longispathus (Saxena and Bhojwani 1993), Adhatoda vaisca (Azad et al. 2003), Phellodendron amurense (Yang et al. 2011, Azad et al. 2005a), and Curcuma caesia (Shahinozzaman et al. 2013) rooting frequency was higher when shoots were rooted on low strength MS. The regenerated plantlets were gradually acclimated and successfully established in the soil under natural conditions (Fig. 1F), with a survival rate of $80.0 \%$. The acclimation procedures for in vitro-regenerated plantlets of $P$. amurense were reported earlier (Azad et al. 2005a).

\section{Acknowledgement}

This work was financially supported by the Ministry of Science and Technology, Bangladesh [BS 142 (73)/ 2015-2016]. The authors also like to thank their colleagues from Department of Botany, Rajshahi University for their constant assistance and co-operation.

\section{References}

Amin MN, Razzaque MA and Akhter S (1992) Axillary shoot proliferation and adventitious rooting in vitro of carambola (Averrhoa carambola L.). Plant Tissue Cult. 2: 7-13.

Azad MAK (2012) Plant regeneration through callus-derived protoplasts of Phellodendron amurense Rupr. BTAIJ. 6(10): 317-326. 
Azad MAK and Amin MN (2013) In vitro organogenesis and plantlet regeneration of pigeonpea [Cajanus cajan (L.) Millsp.]. BTAIJ. 7(1): 16-21.

Azad MAK, MN Amin and F Begum (2003) Rapid clonal propagation of a medicinal plant - Adhatoda vasica Nees. using tissue culture technique. On Line J. Biol. Sci. 3(2): 172-182.

Azad MAK, Yokota S, Ishiguri F, Yahara S and Yoshizawa N (2005b) Histological studies of shoot regeneration system in hypocotyl-derived callus of Phellodendron amurense Rupr. J. For. Res. 10: 377-384.

Azad MAK, Yokota S, Ohkubo T, Andoh Y, Yahara S and Yoshizawa N (2005a) In vitro regeneration of the medicinal woody plant Phellodendron amurense Rupr. through excised leaves. Plant Cell, Tissue and Organ Cult. 80: 43-50.

Bacchetta L, Remotti PC, Bernardini C and Saccardo F (2003) Adventitious shoot regeneration from leaf explants and stem nodes of Lilium. Plant Cell, Tissue and Organ Cult. 74: 37-44.

Bopana N and Saxena S (2008) In vitro propagation of a high value medicinal plant: Asparagus racemosus Willd. In vitro Cell. Dev. Biol.-Plant. 44: 525-532.

Chrubasik S, Droste C, Dragano N, Glimm E and Black A (2006) Effectiveness and tolerability of the herbal mixture asparagus-P on blood pressure in treatment-requiring antihypertensives. Phytomedicine. 13(9-10): 740-742.

Dartsch PC (2008) Effect of asparagus-P on cell metabolism of cultured kidney and inflammation-mediating cells. Phytother Res. 22(11): 1477-1481.

Dartsch PC (2008) The potential of asparagus-P to inactivate reactive oxygen radicals. Phytother Res. 22(2): 217-222.

Gamborg OL, Miller RA and Ojima K (1968) Nutrient requirements of suspension cultures of soybean root cells. Exp. Cell Res. 50: 151-158.

Grubben GJH and Denton OA, eds. (2004) Plant Resources of Tropical Africa 2. Vegetables. PROTA Foundation, Wageningen; Backhuys, Leiden; CTA, Wageningen.

Jang DS, Cuendet M, Fong HH, Pezzuto JM and Kinghorn AD (2004) Constituents of Asparagus officinalis evaluated for inhibitory activity against cyclooxygenase-2. J Agric Food Chem. 52(8): 2218-2222.

Junaid A, Mujib A, Bhat MA and Sharma MP (2006) Somatic embryo proliferation, maturation and germination in Catharanthus roseus. Plant Cell, Tissue and Organ Cult. 84: 325-332.

Kappor LD (2001) Handbook of Ayurvedic Medicinal Plants. CRC Press, LCC, New York, Washington D.C. pp. 55.

Lee K, Jeon H and Kim M (2002) Optimization of a mature embryo-based in vitro culture system for high-frequency somatic embryogenic callus induction and plant regeneration from Japonica rice cultivars. Plant Cell, Tissue and Organ Cult. 71: 237-244.

Leung AY and Foster S (1980) Encyclopedia of common natural ingredients used in food, drugs and cosmetics. New York, NY: J. Wiley and Sons.

Litz RE and Jaiswal VS (1990) Micropropagation of tropical and subtropical fruits. In: PC Debergh and RH Zimmerman (eds.) Micropropagation: Technology and Application, Kluwer Acad. Publ. Dordrecht. The Netherlands. pp. 247-266. 
Lloyd G and McCown B (1981) Commercially feasible micropropagation of mountain laurel, Kalmia latifolia by use of shoot tip culture. Proc. Intl. Plant Prop. Soc. 30: 421-427.

Makris DP and Rossiter JT (2001) Domestic processing of onion bulbs (Allium cepa) and asparagus spears (Asparagus officinalis): Effect on flavonol content and antioxidant status , J. Agric. Food Chem. 49(7): 3216-3222.

Pam B (2010) Asparagus - Liliaceae - Asparagacease. Food \& Wine. The International Wine \& Food Society Europe \& Africa Committee.

Reuther G (1984) Asparagus: Handbook of plant cell culture, Vol. 2. pp. 211-242, New york, McMillan .

Saxena S and Bhojwani SS (1993) In vitro clonal multiplication of 4-year-old plants of the bamboo, Dendrocalamus longispathus Kurz. In vitro Cell Dev. Biol. Plant. 29: 135-142.

Shahinozzaman M, Faruq MO, Ferdous MM, Azad MAK and Amin MN (2013) Direct organogenesis and plant regeneration from cotyledons of a multipurpose tree, Acacia mangium Willd. Current Trends in Biotechnol. Pharma. 7(1): 511-517.

Shahinozzaman M, Ferdous MM, Faruq MO, Azad MAK and Amin MN (2013) Micropropagation of black turmeric (Curcuma caesia Roxb.) through in vitro culture of rhizome bud explants. J. Central European Agril. 14(3): 110-115.

Tawfik A A and Noga G (2002) Cumin regeneration from seedling derived embryogenic callus in response to amended kinetin. Plant Cell, Tissue and Organ Cult. 69: 35-40.

USDA NRCS (2007) The PLANTS Database ( http://plants.usda.gov , June 2009). National Plant Data Center, Baton Rouge, LA 70874-4490 USA.

Yadav U, Lal M and Jaiswal VS (1990) In vitro micropropagation of the tropical fruit trees Syzygium cuminii L. Plant Cell, Tissue and Organ Cult. 21: 87-92.

Yang JL, Zhou CG, Zhao B, Jin CL, Zhang T and Li CH (2011) Rapid direct adventitious shoot organogenesis and plant regeneration from mature seed explants of Phellodendron amurense Rupr. J. Medicinal Plants Res. 5(18): 4560-4565. 